\title{
DEGRADATION OF TOXIC HETEROCYCLIC COMPOUND 2-AMINOPYRIDINE BY USING VOLTAMMETRIC TECHNIQUE: A KINETIC STUDY
}

\author{
Dushyant Gangwar ${ }^{\varpi}$, Rajdeep Malik and Jasvinder Kaur \\ ${ }^{1}$ Department of Chemistry, Gurukula Kangri (Deemed to be University) Haridwar, \\ 249404(Uttarakhand) India \\ Corresponding Author: d27gang@gmail.com
}

\begin{abstract}
Electro-oxidation of 2-Aminopyridine (2-APy) was carried out on a platinum electrode by employing an ecofriendly electrochemical technique, cyclic voltammetry. The variation of the anodic peak current with scan rate and concentration was investigated for the 2-APy and to find out the control of the reaction, kinetics, electrochemical and analytical parameters of the reaction. The electrochemical behavior of the 2-APy at the platinum electrode was a diffusion-controlled process with the two-electron transfer. Kinetic parameters such as standard heterogeneous rate constant $\left(\mathrm{k}^{0}, 1.6684 \times 10^{3} \mathrm{~s}^{-1}\right)$, anodic electron transfer rate constant $\left(\mathrm{k}_{(\mathrm{OX})}, 2.1455 \times 10^{3} \mathrm{~s}^{-1}\right)$, electron transfer coefficient $(\alpha, 0.5369)$ and formal potential $\left(\mathrm{E}^{0}, 1.0499 \mathrm{~V}\right)$ were calculated under the influence of scan rates. The concentration study in the range of $8.0 \times 10^{-3} \mathrm{M}$ to $30.0 \times 10^{-3} \mathrm{M}$ was calibrated, the limit of detection and the limit of quantification were calculated to be $1.9188 \times 10^{-3} \mathrm{M}$ and $6.3962 \times 10^{-3} \mathrm{M}$ respectively.

Keywords: 2-Aminopyridine, Cyclic Voltammetry, Kinetic Parameters, Electro-Oxidation, Water Pollution

RASĀYANJ. Chem., Vol. 14, No.3, 2021
\end{abstract}

\section{INTRODUCTION}

The major industrial development increased the number of environmental pollutants, especially in water and soil sources. ${ }^{1}$ Pharmaceuticals and personal care products are frequently detected in surface water, groundwaters and wastewater because of their extensive use in a wide range of human activities. Thus, these compounds are known as emerging contaminants receive special attention because of their potential impact on the environment and human health. ${ }^{2-4}$

Chronic toxicity and car-cinogenic activity were detected by monoamino-pyridines such as 2-

aminopyridine, 3-aminopyridine and 4-aminopyridine. Including the brain, mono aminopyridines are widely distributed in the body because they readily get absorbed by the skin and gastrointestinal tract. Monoaminopyridines are acutely toxic compounds and studies of animals and humans show that they can block K+ channels. ${ }^{5}$ These are listed by the US Environmental Protection Agency (USEPA) as priority contaminants. ${ }^{6}$

2-APy with the formula $\mathrm{H}_{2} \mathrm{NC}_{5} \mathrm{H}_{4} \mathrm{~N}$ is the derivative of heterocyclic organic compound pyridine. ${ }^{7,8}$ In the manufacture of pharmaceuticals, particularly antihistamines and piroxicam, 2-Aminopyridine is used as an intermediate. In the production of ciclopiroxolamine, diphenpyramide, methaqualone, propiram fumarate, pyrilamine, triprolidine, and zomepirac, 2-Aminopyridine may also be an intermediate. ${ }^{9-11}$ Of the three monoaminopyridines, the largest production appears to be 2-aminopyridine. ${ }^{12}$ Skin irritation, nausea, headache, dizziness, flushing of the extremities, increased blood pressure is caused by the exposure of 2-aminopyridine and high exposure can lead the respiratory failure. ${ }^{13}$

Before discharging into the environment, 2-Aminopyridine must be treated. Thermal incineration and ultrafiltration methods are used to treat the 2-APy, which are not economical. ${ }^{7}$ Fenton and the photofenton oxidation process is time consuming. ${ }^{14}$ Although, in aerobic and anaerobic conditions 2Aminopyridine is not expected to be readily biodegradable. ${ }^{12}$

Electroanalytical methods are superior among the various methods and voltammetry is the right choice. ${ }^{15,1}$

${ }^{6}$ Cyclic voltammetry is an environmentally safe technique to investigate contaminants and other compounds. ${ }^{17}$ Electrochemistry has always given analytical techniques characterized by instrumental

Rasayan J. Chem., 14(3), 1953-1958(2021)

http://doi.org/10.31788/RJC.2021.1436433

This work is licensed under a CC BY 4.0 license. 
simplicity, moderate cost and portability. These techniques have introduced the most promising methods for specific application. ${ }^{18,19}$ It is widely used to determine the mechanism and kinetic parameters of reactions. ${ }^{20,21}$ In this present work, the kinetic and electrochemical behavior of 2-APy in phosphate buffer has been investigated.

\section{Materials and Instrumentation}

\section{EXPERIMENTAL}

2-Aminopyridine was bought from Sigma-Aldrich and used without further purification. A stock solution of 2-APy $\left(1.0 \times 10^{-2} \mathrm{M}\right)$ was prepared in double-distilled water. $\mathrm{pH} 11.2$ Phosphate buffer solution (PBS) $0.2 \mathrm{M}$ was prepared according to the method of Christian and Purdy. ${ }^{22}$ Other reagents used were of analytical or chemical grade. All solutions were prepared with double-distilled water.

An Autolab model PGSTAT 101 potentiostat/galvanost at 663 VA Stand (MetrohmAG, Netherlands) was used to record cyclic voltammetric curves. The voltammetric measurements were carried out using a three-electrode cell with the $\mathrm{Ag} / \mathrm{AgCl} /$ saturated $\mathrm{KCl}$ solution $(3.0 \mathrm{M})$ as reference electrode, a platinum wire $(\mathrm{Pt})$ as an auxiliary electrode and a platinum disk electrode $\left(0.031 \mathrm{~cm}^{2}\right)$, as the working electrode in one compartment. The solution pH calculation was done using Elico LI 120 pH meter (Elico Ltd., India). Before each experiment, the platinum electrode was polished with $0.3 \mu \mathrm{m}$ alumina powder (from SigmaAldrich) on smooth polishing pads to get a shiny cleaned surface. All the experiments have been performed at an ambient temperature of $25 \pm 1^{\circ} \mathrm{C}$

\section{Cyclic voltammetry study of 2-Aminopyridine}

\section{RESULTS AND DISCUSSION}

The cyclic voltammogram obtained for $1.0 \times 10^{-2} \mathrm{M} 2$-APy at a scan rate $20 \mathrm{mVs}^{-1}$ shows a well-defined anodic peak at $+1.0492 \mathrm{~V}$ at $\mathrm{Pt}$ electrode from potential window range +0.6 to $+1.4 \mathrm{~V}$ [Fig.-1B]. No corresponding reduction peak has been found on the reverse scan suggesting that the 2-APy electrode process is an irreversible one.

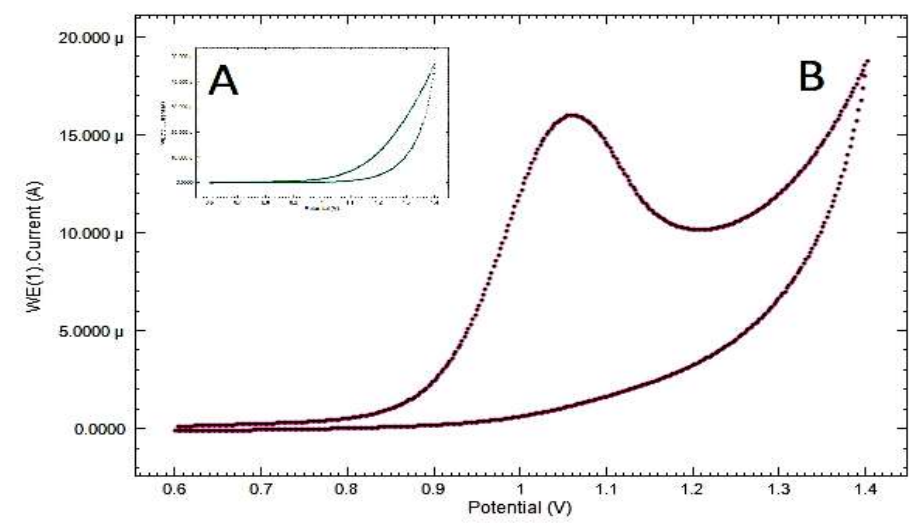

Fig.-1: Cyclic Voltammogram for $1.0 \times 10^{-2} \mathrm{M} 2-\mathrm{APy}$ on Pt electrode in $0.2 \mathrm{M}$ phosphate buffer (A) Blank (B) 2-APy at scan rate $(v)=20 \mathrm{mVs}^{-1}$

\section{Influence of Scan Rate}

The number of successive scans reduces the oxidation current, which maybe because of the adsorption to the electrode surface of 2-APy or its oxidation product [Fig.-2A]. The following CV experiment was to investigate the electrochemical properties of $2 \mathrm{APy}$ and the variation of scan rate can give useful information on the electrode process. The effect of applied scan rate for the oxidation of $1.0 \times 10^{-2} \mathrm{M} \mathrm{2-}$ APy was investigated with different scan rates in the range from $20 \mathrm{mVs}^{-1}-180 \mathrm{mVs}^{-1}$ at Pt electrode [Fig.-2B]. As the scan rate was increased, the peak potential (Epa) for oxidation of 2-APy was also increased.

The plot of anodic peak current (Ipa) versus scan rate $\left(v^{1 / 2}\right)$ [Fig.-3] showed good linearity from the range $20 \mathrm{mV} \mathrm{s}^{-1}-180 \mathrm{mV} \mathrm{s}^{-1}$ with linear correlation coefficient of $\mathrm{r}=0.9886$, Therefore it indicated that the electrode reaction is an irreversible process. Equation can be expressed as:

$$
\operatorname{Ipa}(\mu \mathrm{A})=126.5 \mathrm{v}^{1 / 2}\left(\mathrm{~V}^{1 / 2} \mathrm{~s}^{-1 / 2}\right)-4.829 \quad(\mathrm{r}=0.9886)
$$


RASĀYAN J. Chem.

Vol. 14 | No. 3 |1953-1958| July - September | 2021

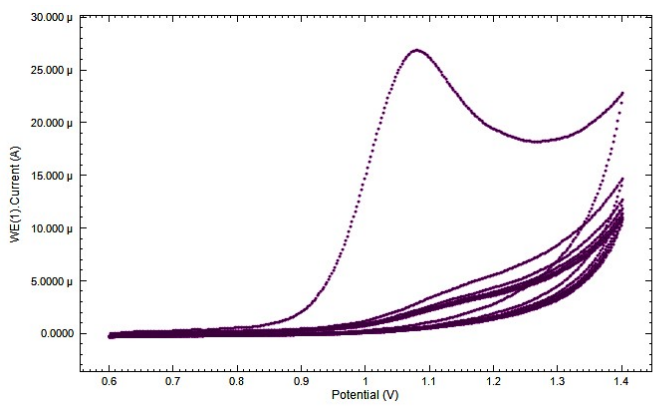

(A)

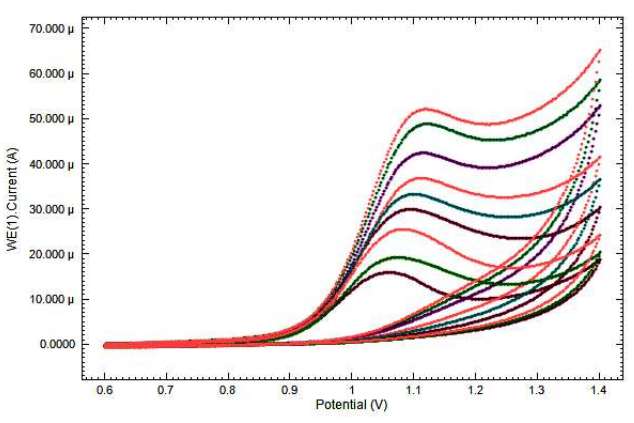

(B)

Fig.-2: Cyclic Voltammograms on Pt Electrode for $1.0 \times 10^{-2} \mathrm{M}$ 2-APy (A) Successive CV obtained at the v= $60 \mathrm{mVs}^{-1}(\mathrm{~B}) \mathrm{CV}$ at different scan rates $\left(20,40,60,80,100,120,140,160\right.$ and $180 \mathrm{mV} \mathrm{s}^{-1}$ respectively) in $0.2 \mathrm{M}$ phosphate buffer ( $\mathrm{pH} 11.2)$

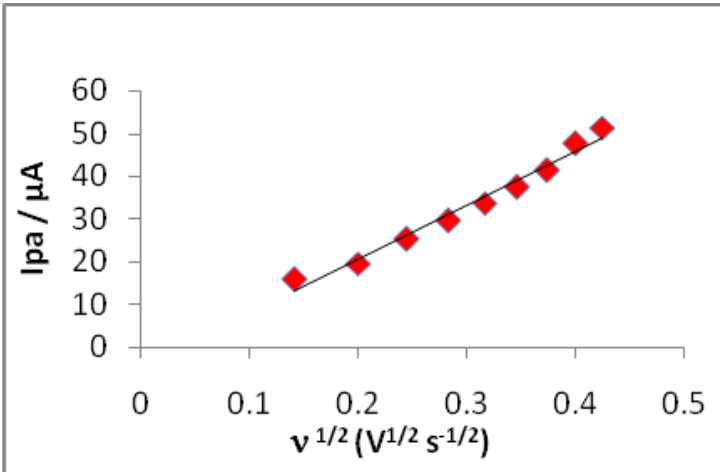

Fig.-3: Ipa vs $v^{1 / 2}$

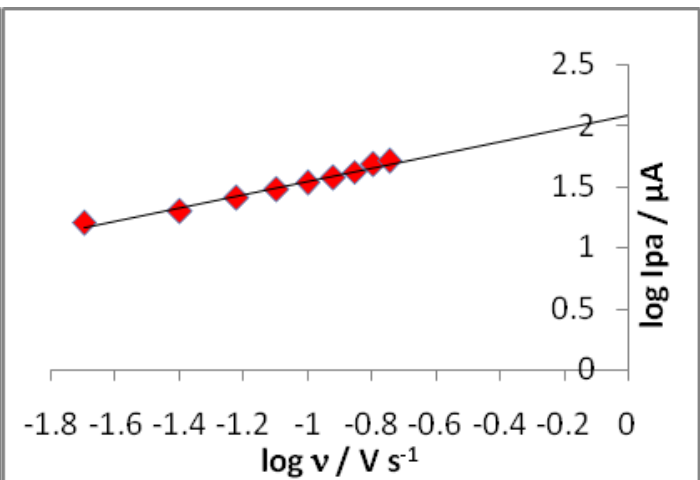

Fig.-4: $\log$ Ipa vs $\log v$

A linear relation between logarithm of anodic peak current (log Ipa) and the logarithm of scan rate $(\log v)$ was observed with the slope value of 0.544 [Fig.-4, Eq.-2]. The observed slope value of 0.544 was comparable with the theoretical value of $0.5^{23,24}$. This was expected for a purely diffusion-controlled process: $:^{25}$

$$
\log \operatorname{Ipa}(\mu \mathrm{A})=0.544 \log v\left(\mathrm{~V} \mathrm{~s}^{-1}\right)+2.086 \quad(\mathrm{r}=0.9891)
$$

So the electro-oxidation of 2-APy is diffusion controlled, and with an increase in the scan rate range of $20 \mathrm{mVs}^{-1}-180 \mathrm{mVs}^{-1}$, Ep shifted to a more positive value, a linear relationship between peak potential and scan rate (Ep and $\log v)$ has been shown in [Fig.-5]

$$
\mathrm{Ep}(\mathrm{V})=0.057 \log v\left(\mathrm{~V} \mathrm{~s}^{-1}\right)+1.142 \quad(\mathrm{r}=0.9849)
$$

According to Laviron, Eq. (4) ${ }^{26}$, for a diffusion-controlled and irreversible electrode process Ep is expressed as:

$E_{P}=E^{0}+\left(\frac{2.303 R T}{\alpha_{\mathrm{nF}}}\right) \log \left(\frac{R T k^{0}}{\alpha_{\mathrm{nF}}}\right)+\left(\frac{2.303 R T}{\alpha_{\mathrm{nF}}}\right) \log V$

Where, ' $\alpha$ ' is the transfer coefficient, $\mathrm{k}^{0}$ is the standard heterogeneous rate constant of the reaction, $\mathrm{n}$ is the number of electrons transferred, $v$ is the scan rate and $\mathrm{E}^{0}$ is the formal standard redox potential, Other symbols have their usual meanings.

Thus, the value of $\alpha$ can be easily calculated from the slope of a plot of Ep versus log $\mathrm{v}$. In our system taking $\mathrm{R}=8.314 \mathrm{JK}^{-1} \mathrm{~mol}^{-1}, \mathrm{~T}=298 \mathrm{~K}$, and $\mathrm{F}=96480 \mathrm{C} \mathrm{mol}^{-1}$. The value of the $\alpha$ was determined to be 1.0375 .

According to Bard and Faulkner ${ }^{20}, \alpha$ value can be evaluated by using Eq.5.

$\alpha=\frac{47.7}{\mathrm{E}_{\mathrm{p}}-\mathrm{E}_{\mathrm{p} / 2}} \mathrm{mV}$ 


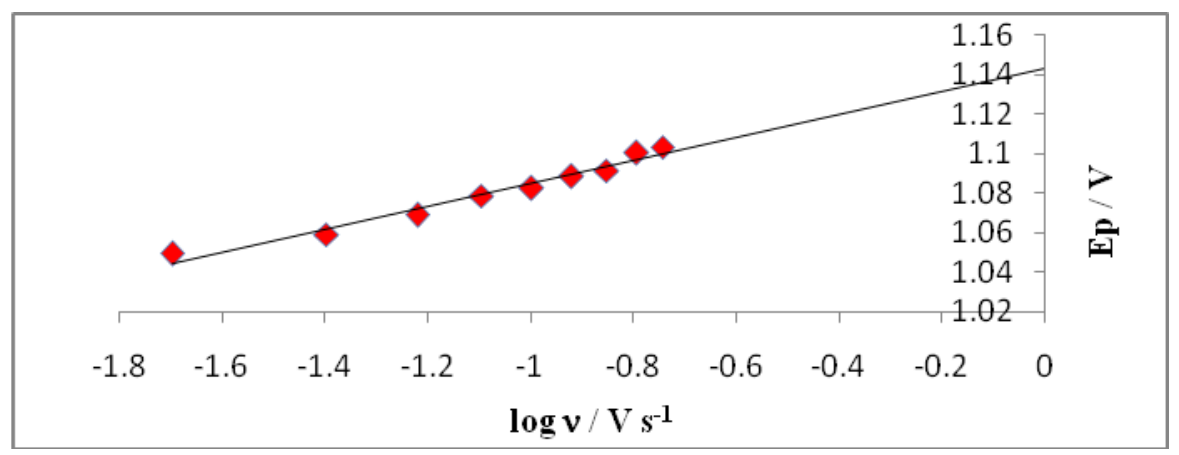

Fig.-5: Ep vs $\log v$

Where, Ep/2 is at half the peak current. The average value of the electron transfer coefficient $(\alpha)$ was evaluated to be 0.5369 . Furthermore, the number of electrons (n) transferred in 2-APy was calculated to be $1.9323 \approx 2$. $\mathrm{k}^{0}$ can be calculated from the intercept of Eq.-3 if the value of the formal potential $\left(\mathrm{E}^{0}\right)$ is known. Formal potential can be determined from the intercept of the peak potential versus scan rate curve by extrapolating to the vertical axis at $\mathrm{v}=0^{27} . \mathrm{k}^{0}$ and $\mathrm{E}^{0}$ were calculated to be $1.6684 \times 10^{3} \mathrm{~s}^{-1}$ and 1.0499 $\mathrm{V}$ respectively. The electron transfer rate constant $\mathrm{k}_{(\mathbf{O x})}$ is a function of the applied potential that can be calculated from the Eq.- $6 .{ }^{28}$

$\mathbf{k}_{(\mathrm{ox})}=\mathbf{k}^{\alpha} \times \exp \left\{-(1-\alpha) \mathbf{n F}\left(\mathbf{E}-\mathbf{E}^{0}\right) / \mathbf{R T}\right\}$

The value of $\mathrm{k}_{(\mathrm{ox})}$ was calculated to be $2.1455 \times 10^{3} \mathrm{~s}^{-1}$.

\section{Effect of 2-APy concentration}

The effect of varying concentrations of 2-APy was also studied at Pt electrode in $0.2 \mathrm{M}$ PBS pH 11.2 at the scan rate of $20 \mathrm{mVs}^{-1}$. With increasing concentrations of 2-APy the cyclic voltammograms revealed that the peak current was linearly increasing with the increasing concentration, as shown in [Fig-6A]. A linear 2-APy calibration curve was obtained in the range from $8.0 \times 10^{-3} \mathrm{M}$ to $30.0 \times 10^{-3} \mathrm{M}$ [Fig.-6B].

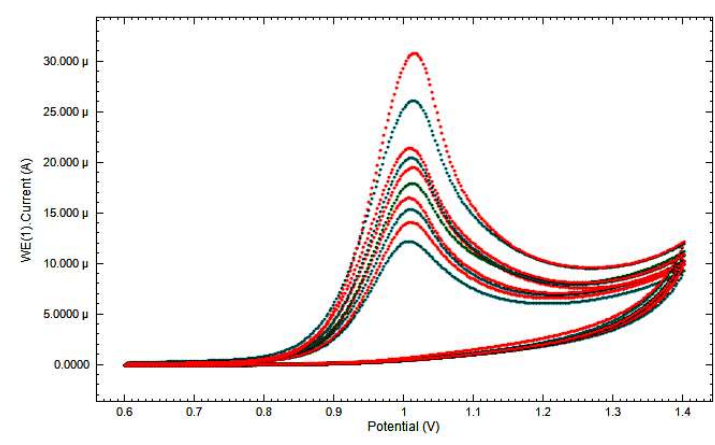

(A)

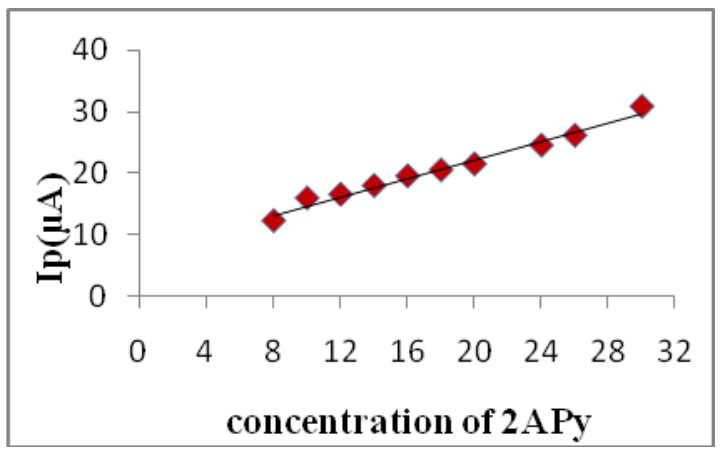

(B)

Fig.-6: (A) Cyclic Voltammograms with increasing concentration of 2-APy in $\mathrm{pH} 11.2$ buffer solution on a platinum electrode with 2-APy concentration: (i) 8.0, (ii) 10.0, (iii) 12.0, (iv) 14.0, (v) 16.0, (vi) 18.0,(vii) 20.0,(viii) 24.0,

(ix) 26.0, and (x) $30.0 \times 10^{-3} \mathrm{M}$ (B) Plot of peak current versus concentration of 2-APy

The linear equation was:

$$
\operatorname{Ipa}(\mu \mathrm{A})=0.747 \mathrm{C}+7.243 \quad \mathrm{r}=0.9899
$$

By using the equation (8) and (9) Detection limit (LOD) and quantification limit (LOQ) have been determined $^{29,30}$. The values of LOD and LOQ were $1.9188 \times 10^{-3} \mathrm{M}$ and $6.3962 \times 10^{-3} \mathrm{M}$ respectively. 
RASĀYAN J. Chem.

Vol. 14 | No. 3 |1953-1958| July - September | 2021

Where $\mathrm{m}$ is the slope of the calibration plot (Eq.-7) and $\mathrm{S}$ is the standard deviation of the six blank measurements.

$$
\begin{aligned}
& \mathrm{LOD}=3 \mathrm{~S} / \mathrm{m} \\
& \mathrm{LOQ}=10 \mathrm{~S} / \mathrm{m}
\end{aligned}
$$

\section{CONCLUSION}

The 2-APy voltammetric behavior and anodic oxidation were investigated by $\mathrm{CV}$ in a $\mathrm{pH} 11.2$ phosphate buffer solution with a platinum electrode. Based on this study, influences of physicochemical parameters like potential scan rate and concentration were investigated. The 2-APy oxidation is a diffusion-controlled with two-electron transfer irreversible process. Therefore, the cyclic voltammetry can quickly and ecofriendly degrade the toxic compound.

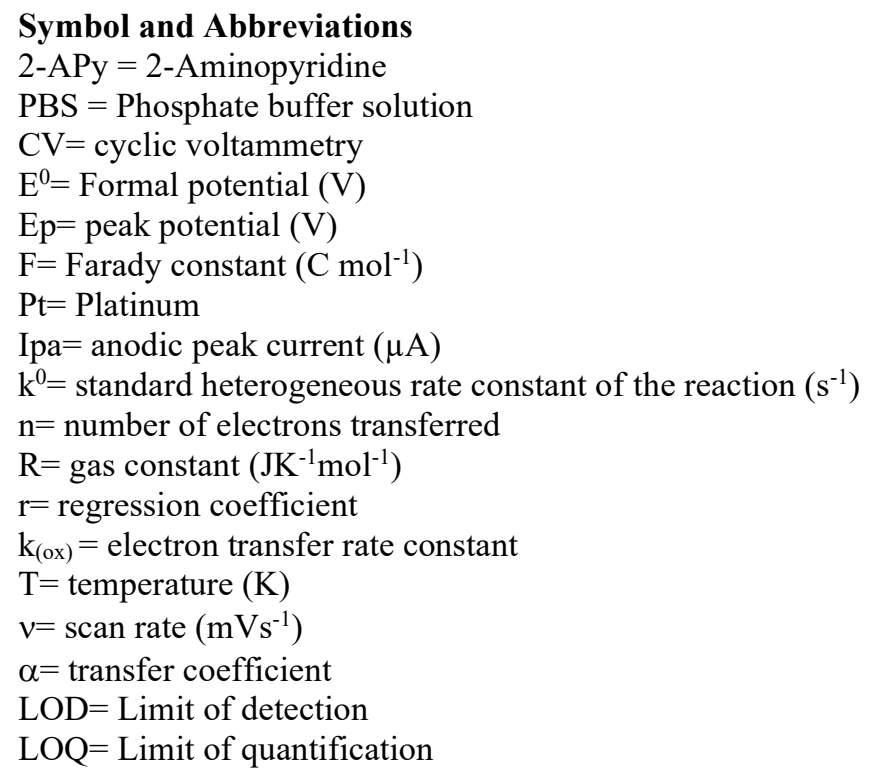

\section{REFERENCES}

1. M. Goto, N. Hayashi, S. Goto, Environmental Science \& Technology, 20(5),463(1986), https://doi.org/10.1021/es00147a004

2. R. Loos, R.Carvalho, D.C. António, S. Comero, G. Locoro, S. Tavazzi, B. Paracchini, M. Ghiani ,T. Lettieri , L. Blaha, B. Jarosova, Water Research, 47(17), 6476(2013), https://doi.org/10.1016/j.watres.2013.08.024

3. N.H. Tran, J. Li , J. Hu, S.L. Ong, Environmental Science and Pollution Research, 21(6),4727(2014), https://doi.org/10.1007/s11356-013-2428-9

4. Q. Sui, X. Cao, S. Lu, W. Zhao, Z. Qiu, G. Yu, Emerging Contaminants, 1(1),15(2015), https://doi.org/10.1016/j.emcon.2015.07.001

5. J.Z. Yeh, G.S. Oxford, C.H. Wu, T. Narahashi, Biophysical Journal, 16(1), 80(1976), https://doi.org/10.1016/S0006-3495(76)85663-9

6. Office of Pesticide Programs, U.S. Environmental Protection Agency, 202 (1980)

7. K. V. Padoley, S. N. Mudliar, R. A. Pandey, Bioresource Technology, 99(10), 4029(2008), https://doi.org/10.1016/j.biortech.2007.01.047

8. S. Shimizu, N. Watanabe, T. Kataoka, T. Shoji, N. Abe, S. Morishita, H. Ichimura, Ullmann's Encyclopedia of Industrial Chemistry, 30(2000), https://doi.org/10.1002/14356007.a22 399

9. G. Carlucci, A. Colanzi, P. Mazzeo, M.G. Quaglia, International Journal of Pharmaceutics, 53(3), 257(1989), https://doi.org/10.1016/0378-5173(89)90321-9

10. R. Lewis, Hawley's Condensed Chemical Dictionary, 14 th ed., John Wiley \& Sons, Inc. (2002)

11. M.Sittig, Pharmaceutical Manufacturing Encyclopedia, 2nded., William AndrewPublishing, Noyes, Knovel Library, 1-2(1988)

12. L. Nora. "Aminopyridine data sheet.” NCI, Technical Resources International, Inc., U.S. (2006)

DEGRADATION OF 2-AMINOPYRIDINE 
RASĀYAN J. Chem.

Vol. 14 | No. 3 |1953-1958| July - September | 2021

13. Documentation of the Threshold Limit Values for Chemical Substances, 7th ed., American Conference of Governmental Industrial Hygienists Inc., Cincinnati, OH, 1(2001)

14. R. Karale, B. Manu, S. Shrihari, International Journal of Advanced Technology in Civil Engineering, 2(1), 96(2013)

15. A. Chatterjee, Research Journal of Pharmacology and Pharmacodynamics, 9(2),88(2017), http://dx.doi.org/10.5958/2321-5836.2017.00015.5

16. N. Ramalakshmi, B. Marichamy, Asian Journal of Research in Chemistry, 4(12),1921(2011)

17. R.S. Nicholson, I. Shain, Analytical Chemistry, 36(4),706(1964)

18. A.K. Jain, V.K. Gupta, L.P. Singh, J.R. Raisoni, Electrochimica Acta, 51(12), 2547 (2006), https://doi.org/10.1016/j.electacta.2005.07.040

19. A. Jain, V. Gupta, L. Singh, Analyst, 122(6), 587(1997), https://doi.org/10.1039/A608421D

20. A.J.Bard, L.R.Faulkner, Electrochemical Methods Fundamentals and Applications, John Wiley \& Sons, (2001)

21. R.G. Compton, C.E. Banks Understanding Voltammetry, Second Edition, Imperial College Press, (2011)

22. G.D. Christian, W.C. Purdy, Journal of Electroanalytical Chemistry, 3(6), 363(1962), https://doi.org/10.1016/0022-0728(62)80012-6

23. M. B. Gholivand, A. R. Jalalvand, H. C. Goicoechea, T. Skov, Talanta, 119, 556(2014), https://doi.org/10.1016/j.talanta.2013.11.028

24. D.K. Gosser, Cyclic Voltammetry, in: Simulation and Analysis of Reaction Mechanisms, VCH, New York, p. 43(1993)

25. J. I. Gowda, S. T. Nandibewoor, Electrochimica Acta, 116, 328(2014), https://doi.org/10.1016/j.electacta.2013.11.014

26. E. Laviron, Journal of Electroanalytical Chemistry and Interfacial Electroichemistry, 101(1), 19 (1979), https://doi.org/10.1016/S0022-0728(79)80075-3

27. Y. $\mathrm{Wu}, \mathrm{X} . \mathrm{Ji}, \mathrm{S} . \mathrm{Hu}, \quad$ Bioelectrochemistry, $\mathbf{6 4 ( 1 ) ,} \quad 95(2004)$, https://doi.org/10.1016/j.bioelechem.2004.03.005

28. J. J. Van Benschoten, J.Y. Lewis, W. R. Heineman, D. A. Roston, P. T. Kissinger, Journal of Chemical Education, 60(9), 772(1983)

29. H. M. Rageh, M. M. Abou-Krisha, A. M. Abo-Bakr, and M. Abd-Elsabour, International Journal of Electrochemical Science, 10, 4110(2015)

30. K.V. Harisha, B.K. Swamy, E. E. Ebenso, Journal of Electroanalytical Chemistry, 823, 730(2018), https://doi.org/10.1016/j.jelechem.2018.07.021

[RJC-6433/2021] 